\title{
Influence of Female Teachers' Reproductive Health Experiences on Their Work Performance in Schools
}

\author{
Tuhiriirwe Hellen ${ }^{1} \&$ Sekiwu Denis ${ }^{2}$ \\ ${ }^{1,2}$ School of Education, Educational Management Department, Kabale University, Kabale, Uganda \\ Correspondence: Tuhiriirwe Hellen, Kabale, Uganda. \\ Email: hellentuhiriirwe@gmail.com
}

DOI: $10.53103 /$ cjess.v1i2.14

\begin{abstract}
In this article, I discussed the influence of female teachers' reproductive health experiences on their work performance in schools. By natural course, females undergo reproductive health changes such as menstruation periods, pregnancy, childcare and nursing which tend to weaken them physically, psychologically and mentally because of the challenges they encounter. This study was carried out to explore the influence of female teachers' reproductive health experiences on their work performance and the coping mechanisms they use while executing their duties and responsibilities. In total, a sample of 45 respondents was selected using purposive sampling. These included Headteachers, Heads of Department, Male teachers and Female teachers. The study employed Qualitative techniques by adopting a phenomenological research design to collect and analyse data. Data collection tools used were the Interview guide, Focus group discussion guide and Documentary review checklist. A qualitative presentation and analysis of data were based on themes formulated based on study objectives. The cultural feminist theory was used to interpret and discuss data. The study findings indicate that female teachers are stigmatized, oppressed, stereotyped and discriminated against at the workplace. These findings are of great importance to the Ministry of Education, school administrators and future researchers as they will guide policy formulation to improve the welfare of female teachers at the workplace. The state through the Ministry of Education and Sports should formulate a public policy agenda on gender equity to promote the welfare and inclusion of female teachers in all departments at the workplace.

Keywords: Female Reproductive Health Experiences, Work Performance.
\end{abstract}

\section{Introduction}

Reproductive Health is a state of complete physical, mental and social wellbeing in matters relating to the functioning of the reproductive systems and processes (Spielberg, 2002). Female reproductive health experiences are specifically defined as numerous sexual changes manifest throughout the female's biological life right away from childhood to adolescence as well as to their pre-natal and post-natal stages (Mattuci, 2005). According to Hanif (2004) female teachers experience more stress at the workplace as they have increased reproductive and maternal experiences compared to their male counterparts. This is because female teachers tend to be confronted with the issue of combining work, prenatal 
and postnatal experiences related to childbirth and care. They are confronted with numerous reproductive health experiences at all stages which in one way or the other great influence their performance. Female teachers' reproductive health experiences are grouped under three stages concerning the working mothers. The first stage is the Nulliparous stage composed of female teachers who have never conceived either by choice or under related conditions. Some experience heavy and painful menstruation periods which cause discomfort to the concerned female teacher. The second stage is of pregnant mothers with experiences of early morning sickness, nausea and general body weakness. They do not find it easy while executing their duties and responsibilities at the workplace. Then another stage is of breastfeeding mothers with child care and nursing activities. All these experiences in one way or the other affect the performance of female teachers. They end up reporting late for duty or even totally missing lessons. After nine months of pregnancy, when a baby is born, child nursing and care is another hectic exercise most especially when it is combined with school duties and responsibilities. These Reproductive Health Experiences confronted at the workplace do pose equity and social justice challenges that were investigated. According to Plattison and Gross (1996) there is so far no special attention paid to female teachers at all levels at the workplace as they try to combine their reproductive experiences with the allocated duties and responsibilities. Bragger, Kutcher, Morgan and Firth (1996) further add that very few studies have specifically put attention to these reproductive experiences that confront female teachers yet their impact on the teachers' productivity ponder complex questions for empirical verification. This study aimed at exploring the influence of reproductive health experiences on the performance of female teachers and how they cope with their work performance.

\section{Literature and Theory}

Historically, for a decade, Uganda has utilized gender equity reforms similar to those of industrialized countries to manage diversity and improve teaching and learning (Kajubi, 1992; Yates 1993; Wilson, 2004). These reforms which include the use of affirmative action and coeducational schooling have increased the number of students at school which is achieved parity while ignoring gender issues such as reproductive health experiences of female teachers embedded in the school culture. The policymakers in Uganda assume that schools are gender-neutral yet gender regimes can be observed in symbols and school practices such as mission statements, curriculum instructions and administrative work (Muhwezi, 2003). The overall gender regimes may undermine the human rights efforts to provide quality education and relevant equal opportunities to boys and girls as well as equitable consideration of female and male teachers. Performance according to Armstrong is the accomplishment of a given task measured against the set standards. It is the degree to which an employee and organizational goals are met.

Workers performance may be traced to the period of scientific management when 
early theorists promoted the idea of setting performance standards and measuring work (Okwo, 2016). The question of measuring work came along with the modern study of Government aided administration when people started advocating for rational scientific management principles designed to improve community service (Pereira \& Romero, 2017). With the emergency of new Government aided management, performance became more pronounced because of the demand for transparency and appropriate managerial methods of controlling and managing administration to have value for money in the school setting. According to Gray, Murphy, Gallagher, and Simpson (2016), many women either leave the profession or lack opportunities for advancement because they are often discriminated against because of their reproductive health experiences. Gray (2016) further argues that women are often given lower ratings on assessment centred tasks when they wore pregnancy prostheses than when they did not and are subjected to interpersonal discrimination when applying for jobs and most of the time is left behind in favour of their male counterparts.

The contextual premise of this study is that if women face several challenges within their reproductive health experiences, how do these challenges affect their performance at work and how do they cope with them. The work of teachers is indispensable and it requires skills, in-depth knowledge, ability and a positive attitude towards learners (Fomsi \& Njoku, 2011). To improve the learning process of students, teachers' performance is still a critical factor in secondary schools most especially after the implementation of Universal Secondary education where students' literate skills are very low especially in rural areas (Ochwo, 2013). Female teachers meet Reproductive health challenges such as menstruation periods associated with Amenorrhea, dysmenorrhea, irregular menses and pregnancy-related complications such as nausea and vomiting, loss of appetite and sometimes heartburn, child nursing and care after a baby is born. All these in one way or another affect female teachers' physical, psychological and social wellbeing in the course of fulfilling their duties and responsibilities.

Consequently, the public service has designated a mandatory maternity leave of sixty working days to women after they have given birth purposely to cater for the newly born baby until such a time when a baby can be left at home and the woman comes back to work. In Uganda, the public standing orders (2010) also provide sixty working days of maternity leave on full pay regardless of status and in case there is a need, the mother can apply for additional off days which shall be offset from her annual leave. The constitution of the Republic of Uganda, (1995) Article 33;2 and 3 state that the state shall provide facilities and opportunities necessary to enhance the welfare of women to enable them to realize the full potential, advancement, unique status and natural maternal functions in society. Some female teachers during menstruation periods feel so sickly that they cannot perform to the expectations of the workstations. This however forces many of them to stay at home or even spend the whole day sleeping at the workplace. Given the fact that 
childbearing mothers are stigmatized and discriminated against by their employers due to their reproductive health situations, the Uganda Government White paper (1992) recommended that both public and private sectors should put in place incentives such as tax holidays for women on maternity leave and recommends the provision of suitable terms and conditions of service to women to motivate them to perform their duties effectively. In Uganda, consideration towards female teachers experiencing Reproductive Health changes is only realized after childbirth by granting mothers sixty working days of maternity leave on full pay but no attention is paid to female teachers under the nulliparous stage with challenges such as heavy and painful menstruation periods and to pregnant mothers with all the discomfort of pregnancies.

The study employed Morgan and Firth's Theory of Cultural Feminism (2002). The theory posits that there is a fundamental biological difference between men and women. Therefore, women are likely to receive negative performance evaluations such as stereotypes, social avoidance and rejection. Their differences compared to those of men are special and should be celebrated most especially when it comes to their reproductive health experiences and obligations. This is expected to enable women to feel less stigmatized which in turn improves their performance at the workplace. According to Echols (2016) the cultural feminist theory advocates for equal valuing of the female abilities and occupation including parenting, respecting female values of care and nurturing and working out to strike a balance between males and females most especially at workplaces. Traditionally, conservative cultures overvalue male features of masculinity and undervalue female features of feminism often regarded as kindness and gentility. Nkeala (2006) asserts that cultural feminists define traditional male behaviour to be associated with superiority complex by undermining the efforts put in by their female counterparts. This is however harmful to society and particular fields including business and politics because, in the real sense, women should be paid salaries and wages when they stay at home attending to their domestic chores, childbirth and care so that they become economically viable. This theory sought to understand whether stigmatization, sexual oppression discrimination and stereotyping are some of the reproductive health challenges facing female teachers at their place of work and how these challenges affect their job performance. These factors reflected in the cultural feminist theory still exist in workplaces applied by school managers and their male counterparts therefore the theory suits my study

Frederick Taylor's Piece rate theory suggests that if people devout many hours to work, their productivity increases. This is because enough time allocated to work helps to build creativity, initiative and dedication to work which increases staff performance (Armstrong, 2001). However, by natural selection, female teachers undergo reproductive health experiences which are likely to derail their productivity and professional time at school. If Taylor's piece-rate theory attaches enormous importance to time as a human productivity variable in organizations, then there is a huge gap in trying to explore how 
female teacher's reproductive health experiences affect their performance at school and in the classroom. Like their male counterparts, female teachers make a contract with their employers to be productive, proactive, innovative and high-level performers on the day of their appointment. However, the way female teachers facing various reproductive health challenges at the workplace cope with the demands of the job, duties and responsibilities as an area that was investigated

\section{Methodology}

A qualitative research approach was employed by this study to gather the information that was context specifically to female teachers and their reproductive health experiences. A phenomenological research design was adopted to explore in details life stories and lived experiences of female teachers' reproductive health experiences on work performance in secondary schools as a social phenomenon. According to Creswell, Hanson Clark Plano and Morales (2007) qualitative research is fundamentally interpretative in that the researcher develops a setting or individual description or analyses data for themes or categories and finally draws conclusions about its meaning personally and theoretically, stating the lessons learnt and offering extra questions to be posted. The study was carried out in Kabale Municipality in Western Uganda .45 Participants (5 Headteachers 10 Heads of department, 15 female teachers and 15 male teachers) were purposively selected. Focus group discussions, interviews and documentary reviews were used to generate data in this study. Data were analysed using Braun and Clarke's six-phase framework thematically based on study objectives. The cultural feminist theory was used to interpret and discuss the presented data to understand the gender perspective and dimension concerning how female reproductive health experiences influence their work performance in the school contextualisation. The researcher used a quick impressionist summary in analyzing data, summarized key findings by noting down the frequency responses of respondents during the interview on various issues such as school administrators and teachers' lived experiences regarding the performance of female teachers and their coping mechanisms. This technique of qualitative data analysis has been chosen because it saves time and is not very expensive. Interviews were listened to attentively to identify emerging themes through sorting, recording and interpretation of the meaning data.

\section{Discussion and Analysis of Findings}

Discussion and analysis of findings were made based on the influence of female

teachers' reproductive health experiences on their job performance and their coping mechanisms in schools. Participants revealed female influence in the domestic arena, health challenges like menstruation periods and childbirth and care, absenteeism, discrimination and marginalization and poor workplace relations. They revealed coping 
mechanisms as avoiding the problem, asking for support, distraction, problem-focused and work schedule.

\section{Female Influence in The Domestic Arena}

The responses of the participants revealed that female influence in the domestic arena greatly affects their work performance. In the African traditional societal settings, both males and females have prescribed roles to play as part of life skills development. Females are supposed to do domestic chores such as cooking, house cleaning, child care and nursing as males attend to public responsibilities like hunting, attending village meetings and holding political offices Tamale (1998). Likewise, most respondents observed that female teachers have long maintained the African traditional order because they tend to give more time and energy to their domestic and biological obligations than their professional mandate, many respondents complained that when female teachers are faced with their reproductive challenges like menstruation periods, pregnancy childbirth and nursing, they tend to be more focused to their marital roles than would be with their school activities. In an interview with a certain headteacher, he stated that

"It gives us trouble allocating sensitive responsibilities to female teachers especially when they are expectant mothers waiting to go for maternity leave. They are so reserved and lazy than their counterparts the male teachers. He further added that in their school, they are interested in recruiting male teachers because they carry no such burdens, are approachable and swift at work."

The above quotation confirms that most school administrators and male coworkers are not interested in working with female teachers as they devote less time to attend to their professional duties and responsibilities which in return reduce their productivity.

\section{Health Challenges}

Female teachers are confronted with various health challenges of a reproductive nature such as menstruation periods, pregnancy childbirth and care. All these in one way or the other affect their work performance. Naturally, females must undergo menstruation periods which are sometimes heavy, painful and sometimes irregular causing a lot of discomfort to the concerned individuals. During this period, some female teachers feel general body weakness and discomfort and cannot effectively attend to their allocated school obligations. Childbirth and care also greatly affect the performance of female teachers most especially when the baby is still very young. After childbirth, according to the public service standing orders (2010) mothers are granted sixty working days of maternity leave on full pay but these days are not enough as the baby cannot be left on its 
own and sometimes the mother is still weak mostly those who give birth under caesarean section

"A female teacher revealed that she experiences heavy and painful menstruation periods which last for a whole week and that she cannot attend to her daily obligations at school. That means her lessons have to be occupied by other teachers which is rather burdensome."

Much as females keep their menstruation periods confidentially, they affect them physically, psychologically, emotionally and socially and as a result, they end up performing poorly in all aspects of the education sector.

\begin{abstract}
Absenteeism
Female teachers are most of the time tied up in their domestic activities mostly especially home management, childbirth and care. Too much time is spent in these activities and sometimes a baby may be sick which is more inconveniencing. When female teachers are pregnant, they as well become uncomfortable. Early pregnancies are associated with early morning sickness, connected to nausea, vomiting and as the pregnancy grows, it becomes heavy to the extent of some female teachers failing to go to school. Much as some international documents support the right to breastfeed as pointed out by Saksena, (2007), mothers do not find it easy and this greatly affects their productivity at the workplace. This is per Skoglund (2021) who asserts that women were given lower ratings especially when they expose their reproductive health experiences. They are subjected to hostile interpersonal discrimination especially when applying for jobs and most of them are left behind in favour of their male counterparts.
\end{abstract}

\title{
Discrimination and Marginalization
}

Female teachers experience discrimination and marginalization from other teachers and school administrators to the extent of being allocated lower classes where students are less demanding. This is a portrayal of the fact that they are regarded as inferior humans to their male counterparts. Females are not put at the same rating as male teachers as put forward by the head of the department who emphasized that females are not allocated extra duties rewarded with extra allowances generalizing them to be inefficient and in return, they feel marginalized and stereotyped as weak sex. According to the cultural feminist theory by Morgan and Firth (2002), it posits that there is a fundamental biological difference between men and women and that women are likely to receive negative performance evaluation, stereotype and rejection at the workplace. Female teachers in some schools are oppressed and marginalized. This was raised in a focus group discussion with female teachers whereby a female teacher revealed that 
"I was abused by the headteacher in front of my students for coming without asking me the cause of my late coming".

This was very embarrassing and degrading and it affects the performance of female teachers both within and outside the classroom.

\section{Poor Workplace Relations}

Some participants revealed that there is a poor workplace relationship between female teachers and their immediate supervisors. Due to their biological experiences surrounding them, they have always been the cause of poor relations at the workplace with their coworkers the male teachers and the immediate supervisors. It is believed that these experiences in one way or the other affect the performance of female teachers at all levels in the school system. This is because, in some circumstances, female teachers are even tempted to miss lessons or arrive late for duty because of their daunting and demanding conditions. This observation was emphasized by a female teacher who lamented that;

"When experiencing menstruation periods (she weeps), they become too heavy and painful to the extent that I cannot come out of bed for a full week"

However, it is universally accepted that those pregnant mothers and those experiencing menstruation periods do not find it easy to conduct their professional duties as expected.

The study findings show how female teachers apply different coping mechanisms at the workplace which include;

\section{Asking for Support}

The results revealed that some female teachers ask for support most especially those who are pregnant as they get general body weakness and fatigue. To some extent, they even fail to attend to their duties and responsibilities. The same applies to breastfeeding mothers most especially when the baby is still young and more demanding. They ask for support from their coworkers who are familiar with the work to be done. This is mostly done by delegating some work to their co-teachers who are relieved somehow so that they can get ample time to attend to their domestic chores most especially of child monitoring and care. This is in line with Majer (2004), who asserts that pregnant mothers and those experiencing various reproductive health changes were aware of how they were or may be treated at work and instead engaged in strategies such as not asking for accommodation within the workplace so that they can keep away from it most especially beyond the normal working time. In a focus group discussion, a female teacher had this to 
say

"When am pregnant, my conditions become unbearable and I end up delegating all the duties allocated to me to my coworkers until after maternity leave when I have recovered from pregnancy and labour fatigue. However, I have to forego all the additional allowances"

As female teachers seek support from their coworkers, they are denied all the allowances and this in return affects them economically since they are not earning during that period.

\section{Distraction}

The findings also revealed that some female teachers employ distraction as a positive coping mechanism that enables them to reduce stressful conditions at the workplace. This enables them to increase their well-being in handling their problems more effectively. This is in line with work-family conflict (2004) asserting that the workplace is structured around an ideal worker who has no childcare responsibilities and can work for a minimum of forty hours per week year-round and can work overtime. In a focus group discussion, female teachers mentioned different ways through which distraction helps them to cope with their job performance by reading newspapers, watching television and other pleasurable activities that can distract them from stressful events. One female teacher emphasized by saying that

"When am confronted by my supervisors about inefficiency brought about by my reproductive experiences especially pregnancy, childbirth and care, I do not usually argue with them instead I get an interesting novel and start reading it. When am at home, I get a piece of cloth and start knitting to keep my mind busy as a way of reducing the stress".

However, with distraction coping techniques, supervisors may feel that female teachers are not paying attention to their reactions which may cause other unexpected problems.

\section{Work Schedule}

Work schedule is another coping mechanism employed by female teachers. This is a technique of allocating time through setting goals, assigning priorities and eliminating time wasters. Because of combining their marital roles with official duties, they find themselves crunched with too much work to be done in little time. A female teacher in a group discussion had this to say

"I make sure that I wake up very early in the morning at around 5.00 am 
then allot my time to different tasks in a realistic way that can be easily followed. I make a daily schedule and list activities that are to be done in their order of priority and ensure that it is followed effectively. This however has helped me to manage my time properly for all my activities."

Considering a school schedule that starts from 8.00 am to $5.00 \mathrm{pm}$, and all the domestic chores awaiting the attention of women, then female teachers have to design a work schedule to attend to different activities more effectively and improve on time management.

\section{Conclusion and Recommendations}

\section{The Conclusion Was Based On Study Objectives as Below}

Based on the study findings, the researcher concluded that reproductive health experiences affect the performance of female teachers. As a result, they are stereotyped, discriminated against, oppressed and stigmatized at the workplace. For female teachers to be effective at the workplace, they need support from the Government, school administrators and their coworkers, the male teachers to be able to balance their domestic chores with professional duties and responsibilities.

\section{Recommendations}

As per the above conclusion, the researcher hereby recommends the following:

The state through the ministry of Education and Sports should train teachers and school administrators in gender skills and how to handle female teachers facing Reproductive Health experiences.

The state should as well formulate a public policy agenda on gender equity to promote the welfare and inclusion of female teachers in all departments at the workplace.

The Ministry of Gender, Labor and economic development should provide alternative sources of income to enable female teachers to improve their livelihood.

School administrators should establish a work schedule to enable female teachers to choose appropriate lessons which favour them.

Female teachers should freely be involved in decision making to ease the implementation of policies that favour them for greater productivity.

\section{References}

Armstrong, M. (2001). A handbook of management techniques: The best-selling guide to modern management methods. Kogan Page Publishers.

Bragger, J. D., Kutcher, E., Morgan, J., \& Firth, P. (2002). The effects of the structured 
interview on reducing biases against pregnant job applicants. Sex Roles, 46(7), 215-226.

Creswell, J. W., Hanson, W. E., Clark Plano, V. L., \& Morales, A. (2007). Qualitative research designs: Selection and implementation. The counselling Psychologist, 35(2), 236-264.

Creswell, J.W. (2007). Qualitative inquiry and research design: Choosing among five approaches (2nd ed.). California, CA: Sage Publications, Inc.

Echols, A. (2016). Retrospective: Tangled up in pleasure and danger. Signs: Journal of women in Culture and Society, 42(1), 11-22.

Fomsi, E. F., \& Njoku, C. (2011). Undergraduate student's readiness for the use of online chat for collaborative learning. TechnoLearn: An International Journal of Educational Technology, 1(1), 1-11.

Furst, D. E., Khanna, D., Mattucci-Cerinic, M., Silman, A. J., Merkel, P. A., \& Foeldvari, I. (2005). Scleroderma-developing measures of response. The Journal of Rheumatology, 32(12), 2477-2480.

Goff, D. C., Lloyd-Jones, D. M., Bennett, G., Coady, S., D’agostino, R. B., Gibbons, R., ... \& Wilson, P. W. (2014). 2013 ACC/AHA guideline on the assessment of cardiovascular risk: A report of the American College of Cardiology/American Heart Association Task Force on Practice Guidelines. Journal of the American College of Cardiology, 63(25 Part B), 2935-2959.

Government, U. (1992). Education for national integration and development. Government white paper on implementation of the recommendation of the report of the education policy review commission.

Gray, P. M., Murphy, M. H., Gallagher, A. M., \& Simpson, E. E. (2016). Motives and barriers to physical activity among older adults of different socioeconomic status. Journal of Aging and Physical Activity, 24(3), 419-429.

Hanif, A., Bakopoulos, V., \& Dimitriadis, G. J. (2004). Maternal transfer of humoral specific and non-specific immune parameters to sea bream (Sparus Aurata) larvae. Fish \& Shellfish Immunology, 17(5), 411-435.

Kajubi, S. (1992). The Government White Paper on implementation of the recommendations of the report of education policy entitled "education for national integration and development" Kampala: Ministry of Education, Uganda.

Majer, J. M. (2004). Optimism, abstinence self-efficacy, and self-mastery among Oxford House residents. DePaul University.

Morgan, J., \& Firth, P., Bragger, J. D., Kutcher, E., (2002). The effects of the structured interview on reducing biases against pregnant job applicants. Sex Roles, 46(7), 215-226.

Muhwezi, D. K. (2003). Gender-sensitive educational policy and practice: Uganda case study. International Bureau of Education.

Ochwo, P. (2013). Pupil, teacher, and school factors that influence student achievement on the primary leaving examination in Uganda: Measure development and multilevel modelling. Kent State University.

Okwo, C. R. (2016). Demographic characteristics as predictors of social competence and emotional intelligence of secondary school students in Nsukka, Enugu State, Nigeria (Doctoral dissertation). 
Pattison, H., \& Gross, H. (1996). Pregnancy, work and women's well-being: A review. Work \& Stress, 10(1), 72-87.

Pereira, A. C., \& Romero, F. (2017). A review of the meanings and the implications of the industry 4.0 concept. Procedia Manufacturing, 13, 1206-1214.

Romm, N. R. (2018). Responsible research practice: Revisiting transformative paradigm in social research. Springer.

Saksena, A. (2007). CEDAW: Mandate for substantive equality. Indian Journal of Gender Studies, 14(3), 481-498.

Skoglund, E. (2021). Evolution of gender role attitudes and gender equality in Russia. In Gendering post-Soviet space (pp. 3-26). Springer, Singapore.

Tamale, S. (1998). The limitation of affirmative action in Uganda. Woman's World, 15. Uganda. (1995). Constitution of the Republic of Uganda. Uganda Print. and Publishing Corporation.

Yates, J. (1993). Control through communication: The rise of system in American management (Vol. 6). JHU Press. 